\title{
Distribution of Mode I Stress Intensity Factors for Single Circumferential Semi-Elliptical Crack in Thick Cylinder
}

\author{
O. M. Al-Moayed ${ }^{1, ~ *}$, A. K. Kareem ${ }^{1,2}$, A. E. Ismail ${ }^{1}$, S. Jamian ${ }^{1}$, M. N. Nemah ${ }^{1,3}$ \\ ${ }^{1}$ Faculty of Mechanical and Manufacturing Engineering, University Tun Hussein Onn Malaysia, Batu Pahat, 86400, \\ MALAYSIA
}

${ }^{2}$ Faculty of Air Conditioning and Refrigeration Techniques Engineering, Department, Al-Mustaqbal University College, Babylon, IRAQ

${ }^{3}$ Engineering Technical College-Najaf, Al-Furat Al-Awsat Technical University, Najaf, 32001, IRAQ

*Corresponding Author

DOI: https://doi.org/10.30880/ijie.2019.11.07.014

Received 09 October 2019; Accepted 25 October 2019; Available online 15 November 2019

\begin{abstract}
In this paper, mode I stress intensity factors (SIFs) are calculated numerically by finite element software ANSYS, for a single semi-elliptical circumferential crack on a thick cylinder. The examined cracks were located either on the external or internal surface of the cylinder and subjected to two different types of loadings, tension and internal pressure, applied separately. To present results in a more comprehensive form, dimensionless analysis is used, and a wide variation limit of parameters that define the crack geometry is considered. The ratio of crack depth to crack length ranging between 0.4 to 1.2 , the ratio of crack depth to cylinder wall thickness vary between $0.2,0.5$ and 0.8 , and the ratio of the cylinder wall thickness to the cylinder internal radius 0.25 . Based on the obtained results, distributions of SIFs found to be symmetric along the crack front. The location where the maximum SIFs on the crack front attained is strongly affected by the change of aspect ratio, and external cracks generally exhibit a higher SIFs than those of internal cracks. It is also found a significant effect for the relative depth of the crack on SIFs value, which could accelerate the fracture process.
\end{abstract}

Keywords: Stress intensity factors (SIFs), ANSYS, surface crack, semi-elliptical crack

\section{Introduction}

In general, the cylindrical bodies, for example, pipes and pressure vessels, play an essential role in the industry due to their extensive usage. The structural integrity of these structures considered a vital issue in term of safety or cost. The failure of such structures has been triggered by the existence of surface cracks, where defects like cracks can be observed in this kind of structures, which traced to the manufacturing faults or pitting corrosion that can produce cracks within the structure. Basically, cracks can be divided according to its location on the pipes or hollow cylinders into three types, they are axial, circumferential (or surface cracks), and inclined cracks. All the mentioned types could be external or internal surface cracks depend on its position on the outer and inner surface of the cylinder, respectively. These cracks initiate with an irregular shape, but after few cyclic loadings, it takes approximately a semi-elliptical form, which has been proved by Lin and Smith [1], and for this reason, most of the researchers used this shape in their studies. Semi-elliptical surface cracks considered one of the most common profiles of defects in pipes and hollow cylinders as mentioned by Raju and Newman [2], and Li and Yang [3], a semi-elliptical crack schematic and geometry located on a hollow cylinder are shown in Figure 1.

In order to predict the failure of hollow cylinders or pipes which contain semi-elliptical crack, it is necessary to accurately calculate the stress intensity factors (SIFs) along the crack front. Therefore, SIFs has great technical importance from an industrial point of view. The first attempt to solve the problem of a cracked cylinder performed by 

Underwood [4], where the engineering estimation has been used, but, this study did not take in consideration the effect of the wall thickness. According to Diamantoudis and Labeas [5] the numerical methods considered among the most reliable and accurate methods used to calculate the SIFs. Ismail et al [6] reviewed the use of finite element program ANSYS to calculate the fracture mechanics parameters in analyzing the engineering structures containing defects or cracks. Various researches have been conducted to estimate SIFs for semi-elliptical cracks. Ismail et al. [7,8] reported the SIF results for a surface crack in a round bar under bending, torsion, and mixed-mode loadings. Shin and Cai [9] evaluated the SIFs of a semielliptical surface crack in a rod for different crack aspect ratios by the experiments and numerical modeling using ABAQUS finite element analysis (FEA) codes.

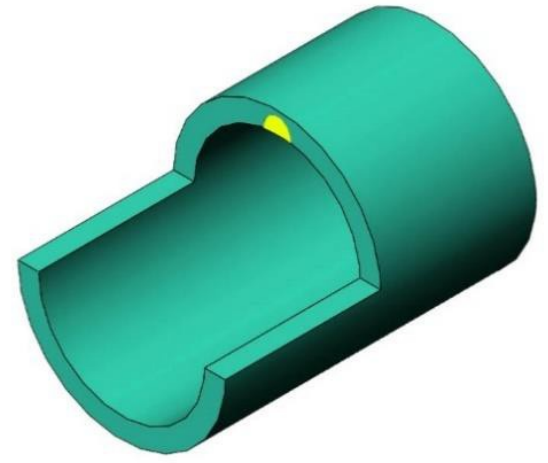

(a)

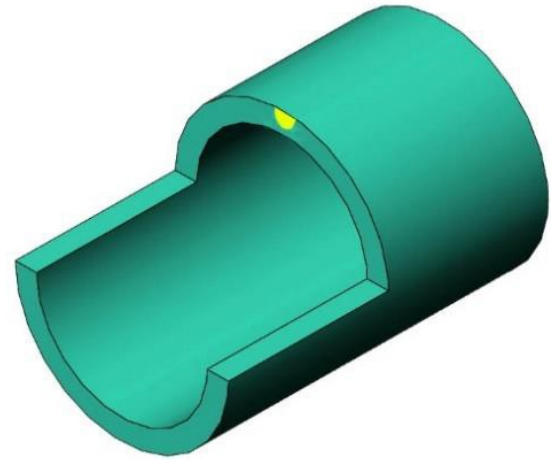

(b)

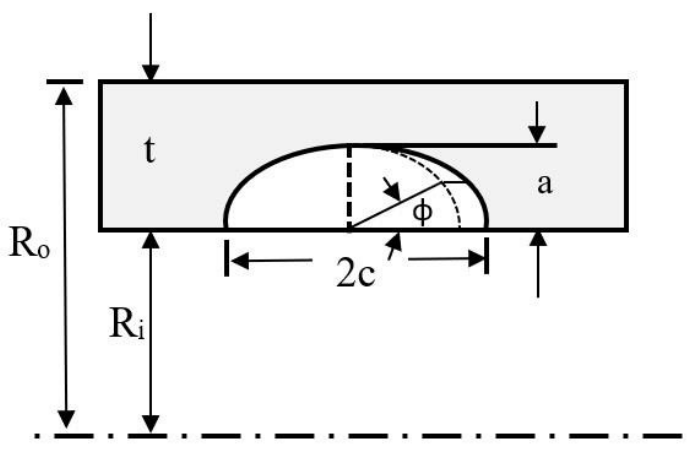

(c)

Fig. 1- The layout of the problem (a) cylinder with internal semi-elliptical crack, (b) cylinder with external semielliptical crack, (c) cross-sectional geometry of the semi-elliptical crack.

Raju and Newman [2] applied three-dimensional finite element to analyze the SIFs for longitudinal cracks in pressurized cylinders, this analysis was limited to mode I. However, SIFs presented in their study applicable to cases with crack aspect ratio ( $a / c$, crack depth to crack length ratio), $0.2 \leq a / c \leq 1.0$. Wang and Lambert [10] used a 3-D finite element analysis and weight function method to extend the crack aspect ratio to be between 0 to 1.0. Fett [11] modified a procedure to determine SIFs by using weight function for semi-elliptical cracks for a crack aspect ratio greater than 1.0, this method dedicated for 2D surface cracks, and the application limited to a variety of loading distributions. Another study conducted by Shahani and Habibi [12] used 3-D FEA to calculate SIFs distribution along the crack front for an external circumferential crack subjected to mix-mode loading. Predan et al [13] applied the FE method to solve the problem of the cracked hollow cylinder under torsional loading.

Carpinteri et al [14] and, Carpinteri and Brighenti [15] analyzed the problem of a hollow cylinder with circumferential edge crack under bending moment and axial loading separately, where the 3-D FE modeling was used. Raju and Newman [16] applied 3-D FEA for a wide range of circumferential semi-elliptical cracks located on pipes and rods. However, despite the available solutions in the literature, but according to Zareei and Nabavi [17], there is no complete solution. Most of the conducted studies dealt with either external or internal crack, considering the two surfaces cracks, along with a wide range of crack geometry, seems to be very rare.

In this paper, mode I SIFs were calculated, for a semi-elliptical circumferential crack located either on the external or internal surface of a thick cylinder subjected to tension and internal pressure separately, as shown in Figure 1. Different crack geometries were used to cover wide ranges of crack shapes, for crack aspect ratio (ratio of crack depth to crack length), ranging between 0.4 to 1.2 . For each value of crack aspect ratio, three values of the relative crack depth ratio (ratio of crack depth to cylinder wall thickness), varying between $0.2,0.5$, and 0.8 . The analysis conducted 
after the proposed model validated with the available in the literature then results presented in the non-dimensional form of SIFs (normalized SIFs).

\section{Finite element modeling}

In this study, mode I SIFs for semi-elliptical crack located either on the external or internal surface of a thick cylinder, subjected to tension and internal pressure loadings applied separately calculated by ANSYS, finite element software [18]. A thick cylinder with total length, $L$, outer radius, $R_{o}$, inner radius, $R_{i}$, and wall thickness, $t$, containing single semi-elliptical circumferential surface crack of depth $a$ and length $2 c$, located on the inner and outer surfaces of the cylinder as shown in Figure 1.

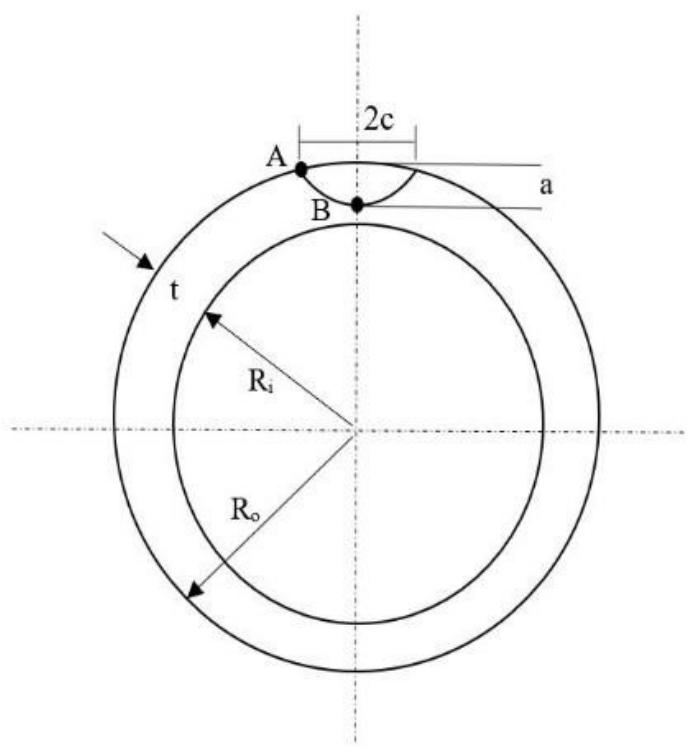

(a)

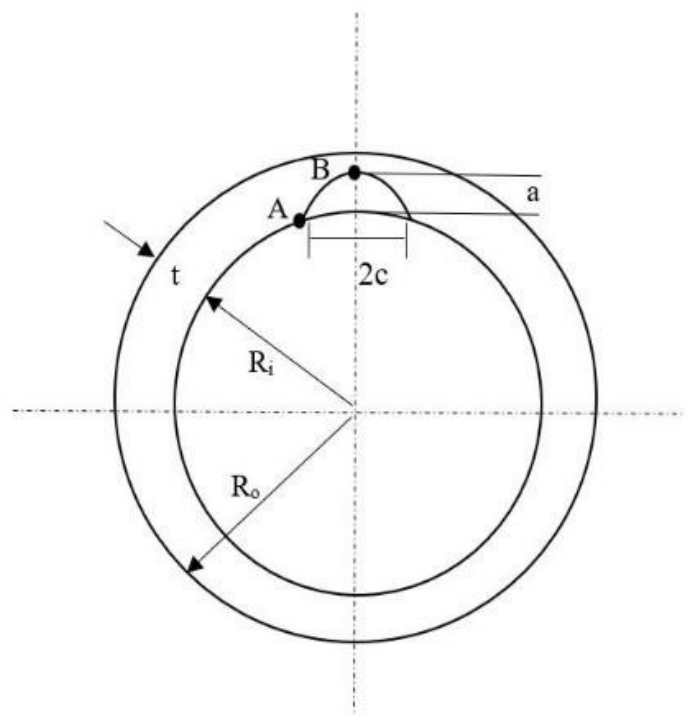

(b)

Fig. 2- Cross-section of a cylinder with (a) external, and (b) internal circumferential semi-elliptical cracks.

Generally, the crack geometry can be described by two dimensionless parameters, $a / c$ and $a / t$, the so-called crack aspect ratio and relative depth of the crack, respectively. Any arbitrary point on the crack front can be defined by a nondimensional coordinate regarded as normalized coordinate, $2 \phi / \pi$, where $\phi$, is the parametric angle of elliptical crack. The crack aspect ratio of the semi-elliptical crack changes from 0.4 to 1.2 and the relative depth of the crack varies between $0.2,0.5$ and 0.8 . The ratio of the external to internal radius of the cylinder in all considered cases assumed to be $R_{o} / R_{i}=1.25$ and $t / R_{i}=0.25$, the Poisson's ratio assumed to be 0.3 , and Young's modulus is $200 \mathrm{GPa}$. Due to the symmetry of the SIFs distribution along the crack front, therefore, SIFs values for one half of the crack front were plotted, and the normalized coordinates, ranging from 0 to 1, points (B and A) Figure 2, representing the deepest and outer point (surface point) of the crack front respectively.

The cylinder is modeled, then meshed, and the boundary conditions were applied. Because of the rapid changes of the geometrical parameters in the region around the crack front, special care taken for this region, where a very fine mesh is used for this area, while a coarse mesh is used elsewhere, as shown in Figure 3. As mentioned before, two types of crack positions were examined for the cylinder, external or internal semi-elliptical circumferential crack as shown in Figure 2, subjected to tension and internal pressure separately, furthermore, thick cylinder with external crack examined under tension first, and then under internal pressure, the same procedure followed for the internal crack also. The applied load kept in the elastic limits in order to avoid large plastic deformations. For tension, the load is applied remotely to one end of the cylinder, and the other end fixed, while for the internal pressure loading, the pressure applied to the interior surface of the cylinder, and the two ends of the cylinder are fixed.

The use of ANSYS provides the ability to create a number of contours around the crack tips along the crack front. For this study, six contours around the crack front were created, and SIFs for each contour along the crack front were calculated. A proper selection for which contour gives more reliable results considered an important task, this is because of the large material shrinkage in the region close to the crack tips as mentioned by Ismail [19]. Therefore, the results of the 5th contour were selected. Because of the advantage that the application of non-dimensional analysis offers, this method is employed here, the calculated stress intensity factors, normalized according to the following relationships, Raju and Newman $[2,16]$ : 


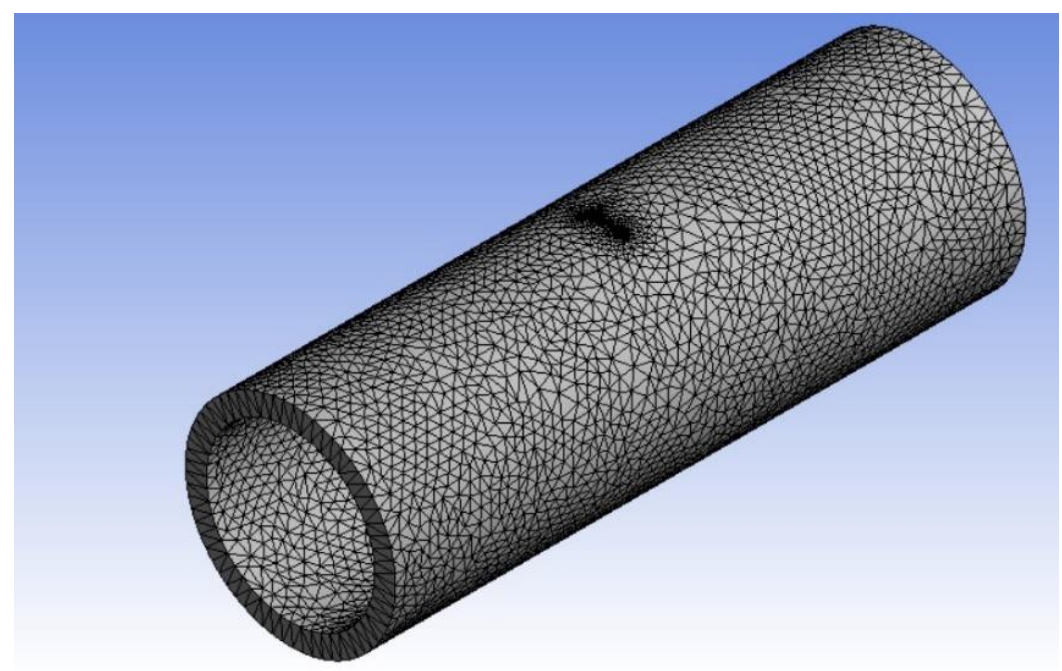

(a)

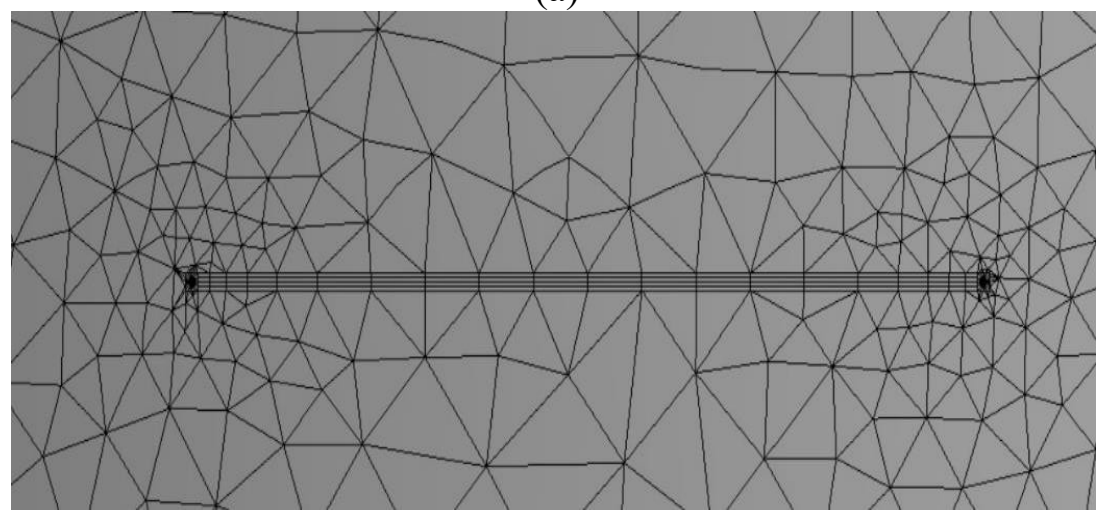

(b)

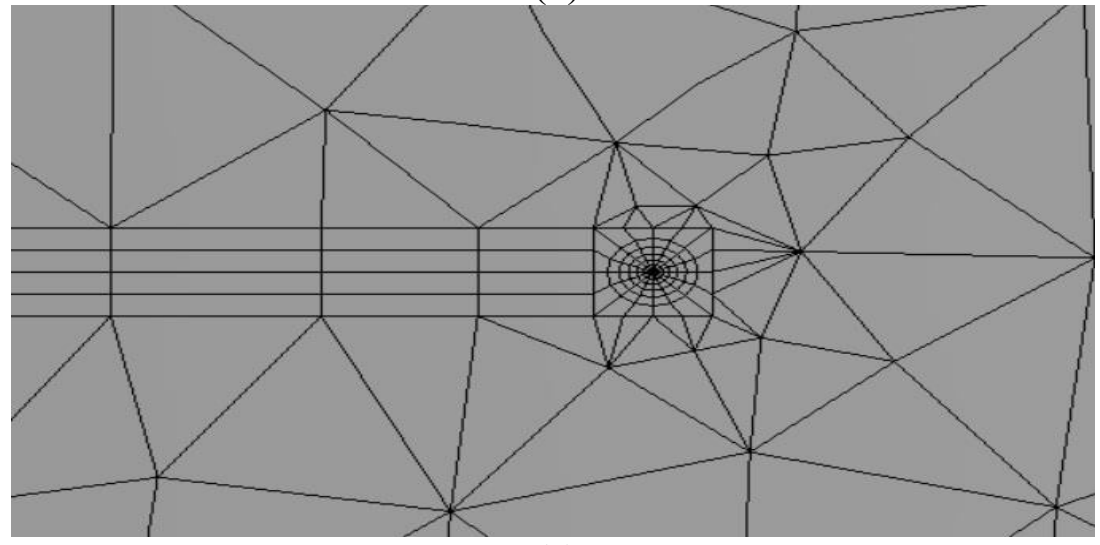

(c)

Fig. 3- Finite Element model (a) the complete cylinder, (b) region around crack tips, and (c) close to the crack tip.

$$
\begin{aligned}
& F_{i}=\frac{]_{c}}{p-} \\
& \text { 一回回/ }
\end{aligned}
$$

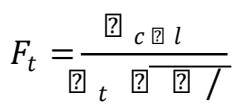


Where $F_{i}$ and $F_{t}=$ SIFs coefficients for internal pressure and tension loading respectively, $K_{c a l}=$ the calculated SIF, $P R / t=$ the average hoop stress, $p=$ applied internal pressure, $\sigma_{t}=$ axial stress $=F / \pi\left(R^{2}{ }_{o}-R^{2}{ }^{2}\right)$, where $F$ is the applied remote tension force, $\mathrm{Q}=$ shape factor for elliptical crack, which is calculated by the following equations Raju and Newman [16]:

$$
\begin{aligned}
& =1+1.464\left({ }^{a} \text { 回 }\right)^{1.65} \\
& =1+1.464\left({ }^{c} \text { 回 }\right)^{1.65}
\end{aligned}
$$

for $\mathrm{a} / \mathrm{c} \leq 1$
for $\mathrm{a} / \mathrm{c}>1$

\section{Result and discussion}

Before proceeding the analysis procedure, it is a crucial task to check the validity of the proposed model with the available models in the literature, Raju and Newman [2], therefore, $F_{\text {axial }}$, the normalized SIFs (or dimensionless SIFs coefficients) of an axial crack for the current model were compared to those of Raju and Newman [2], Figure 4 shows the comparison of the dimensionless SIFs, as a function of the normalized crack front position (or normalized coordinate system), where same crack geometry parameters used in both studies. The results showed that the proposed model is in good agreement and it is eligible to pursue further analysis for the other crack configurations.

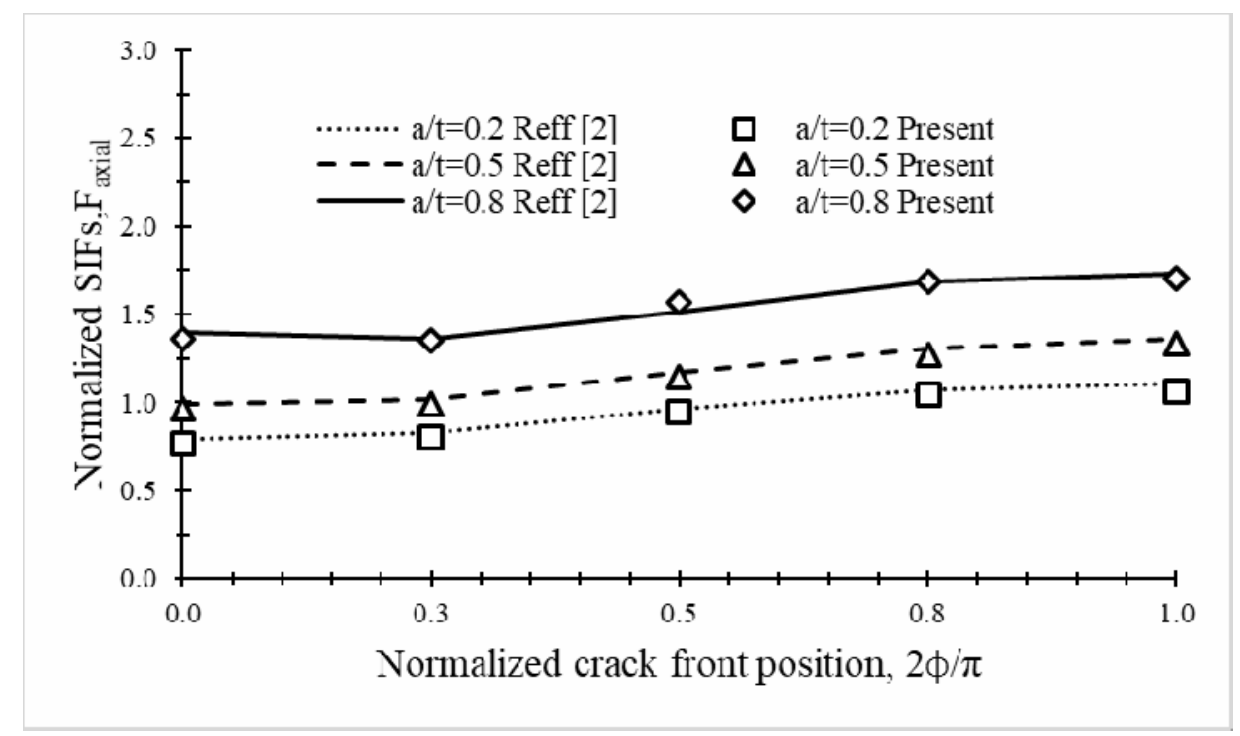

Fig. 4- Validation of the finite element model of the present study, for an axial crack under internal pressure loading.

\subsection{Cracked cylinder under remote tension}

A thick cylinder containing single circumferential semi-elliptical crack, subjected to remote tension, has been analyzed. Two crack positions were examined, external and internal circumferential cracks, which represents cracks located on the external and internal surface of the cylinder respectively. The applied crack geometry parameters, $a / c$, crack aspect ratio ranging between 0.4 to 1.2 , and $a / t$, relative crack depth varies between $0.2,0.5$ and 0.8 . The same geometrical parameters were used for both external and internal crack, besides, the applied load was the same also.

Figure 5 shows the normalized SIFs, $F_{t}$ (normalized SIFs or SIFs coefficients under tension loading), in terms of normalized coordinates of the crack front for different values of crack aspect ratios and relative crack depth for an external semi-elliptical crack under remote tension loading. The results reviled that, the SIFs distributions were symmetric along the crack front, for all examined crack aspect ratios and relative crack depth ratios, therefore, values of SIFs between the deepest point B, and surface point A on the crack front were given. For $a / c \leq 0.6$, SIFs values were convex, and the maximum SIFs value located at point B, then decrease gradually till reach the minimum value at point A. While for $0.6<a / c<0.75$, SIFs values tend to be following approximately a straight line, where the values of SIFs at points $\mathrm{B}$ and $\mathrm{A}$ are approximately equal, and this is an introduction stage to a phenomenon, which is well-known as the transition effect, where the maximum value of SIFs moves from the deepest point on the crack front to surface point, Carpinteri [21]. For $a / c>0.8$, SIFs values along the crack front were distributed on a curve following concave shape, where the highest value of SIFs located near the surface point and decrease gradually towards the deepest point 
where the position of minimum value. In general, the effect of $a / t$ for the all examined cases is similar, where the $F_{t}$ values increase with the increase of relative crack depth ratios, which indicate that, as the crack is more deeper, leads to presents high $F_{t}$ values and vice versa.

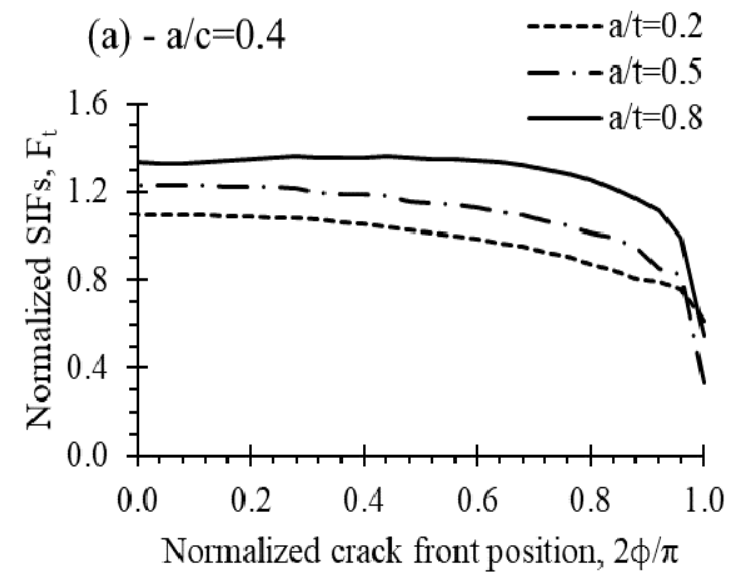

(c) $-\mathrm{a} / \mathrm{c}=0.8$

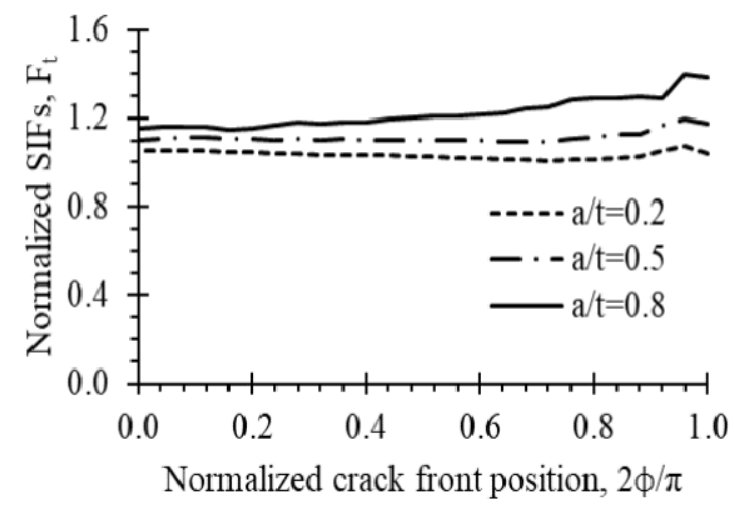

(b) $-\mathrm{a} / \mathrm{c}=0.6$

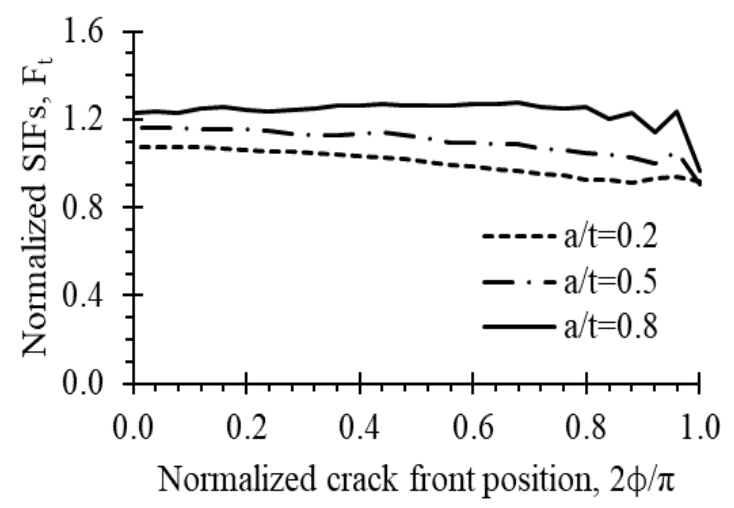

(d) $-\mathrm{a} / \mathrm{c}=1$

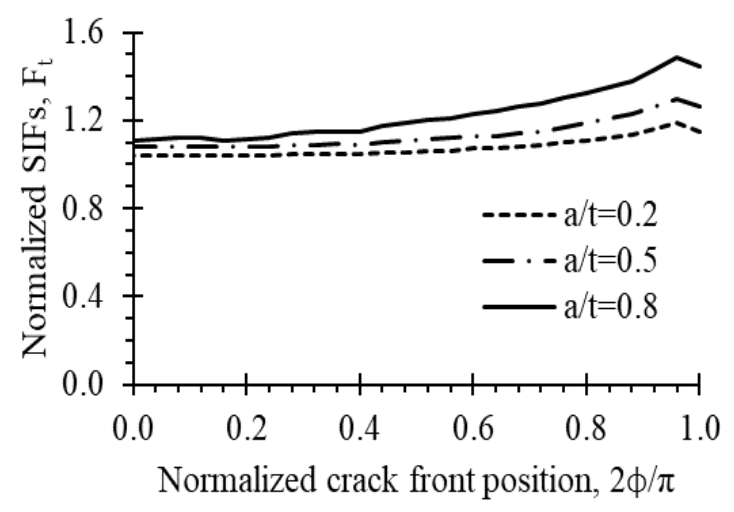

(e)- $\mathrm{a} / \mathrm{c}=1.2$

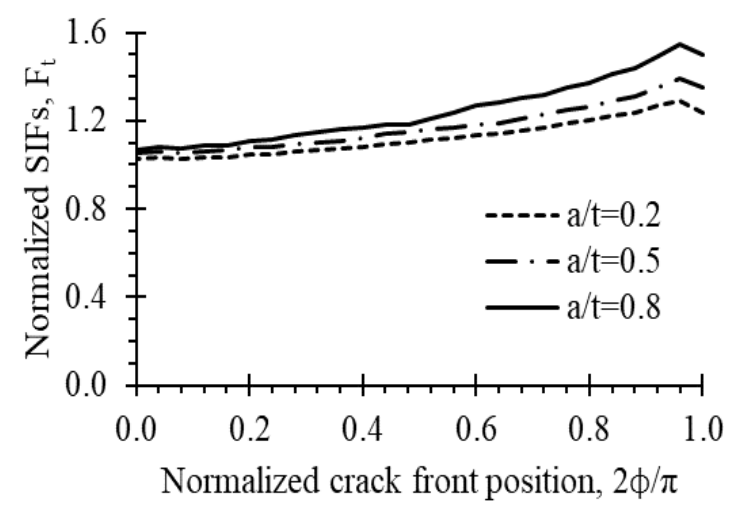

Fig. 5- The normalized stress intensity factors along the crack front for external semi-elliptical crack located on a cylinder subjected to remote tension where (a) $\mathrm{a} / \mathrm{c}=0.4$ (b) $\mathrm{a} / \mathrm{c}=0.6$ (c) $\mathrm{a} / \mathrm{c}=0.8$ (d) $\mathrm{a} / \mathrm{c}=1$, and (e) $\mathrm{a} / \mathrm{c}=1.2$.

Figure 6 shows the value of the normalized SIFs for an internal crack, under tension loading where the same values for $a / c$ and $a / t$ which have been used for the external crack applied also. The behavior almost the same, and the transition effect can also be noticed. The relative crack depth ratio has the same effect, which was shown for external crack, where higher SIFs values attained when the relative crack depth ratio is high, and SIFs decrease with any decrease in relative crack depth ratio. Furthermore, SIFs values for external crack are generally higher than those of 
internal crack with an aspect ratio greater than 0.6 , while for aspect ratio less than 0.6 , SIFs values for internal crack are generally higher.

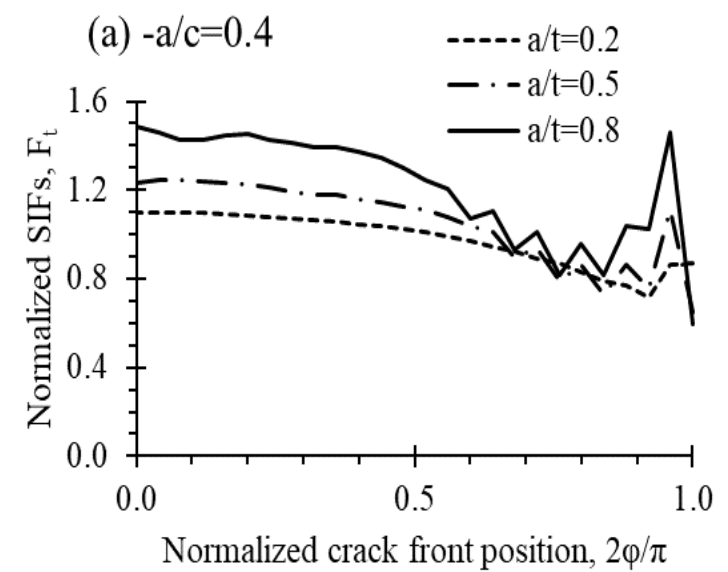

(c) $-\mathrm{a} / \mathrm{c}=0.8$

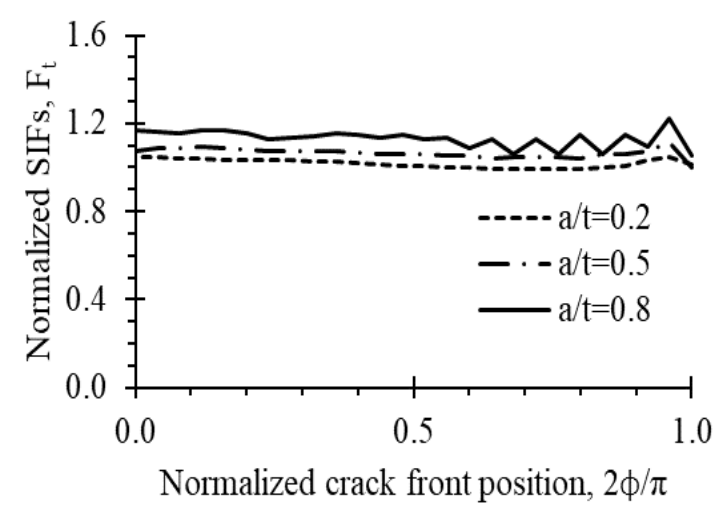

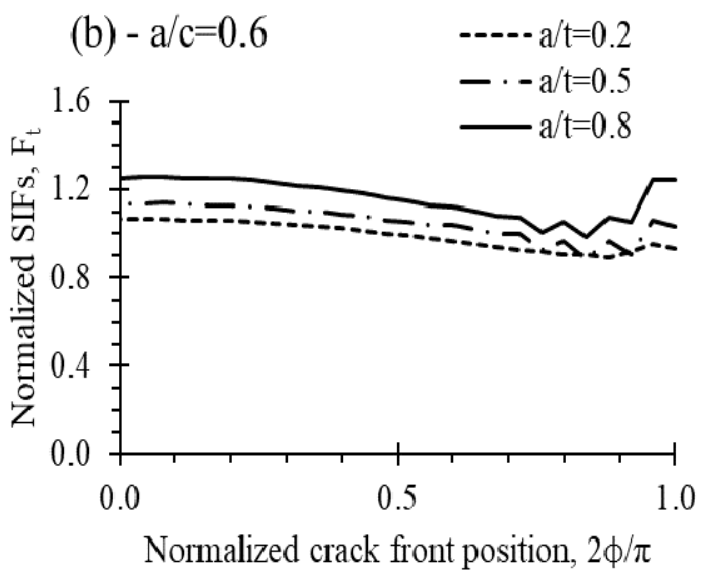

(d) $-\mathrm{a} / \mathrm{c}=1$

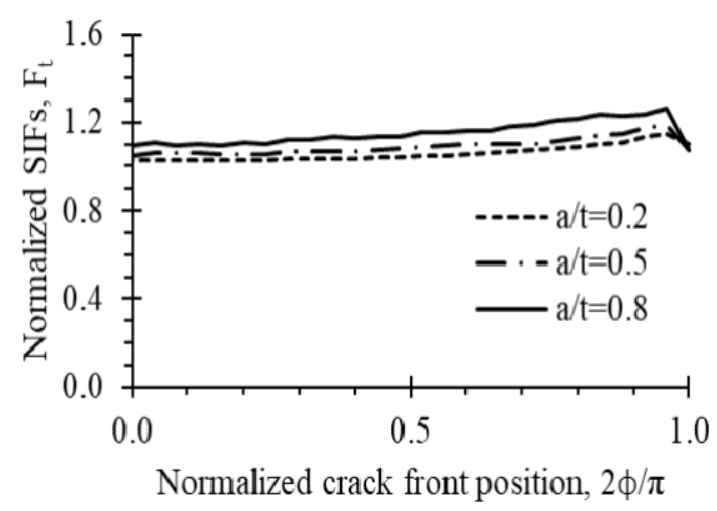

(e) $-\mathrm{a} / \mathrm{c}=1.2$

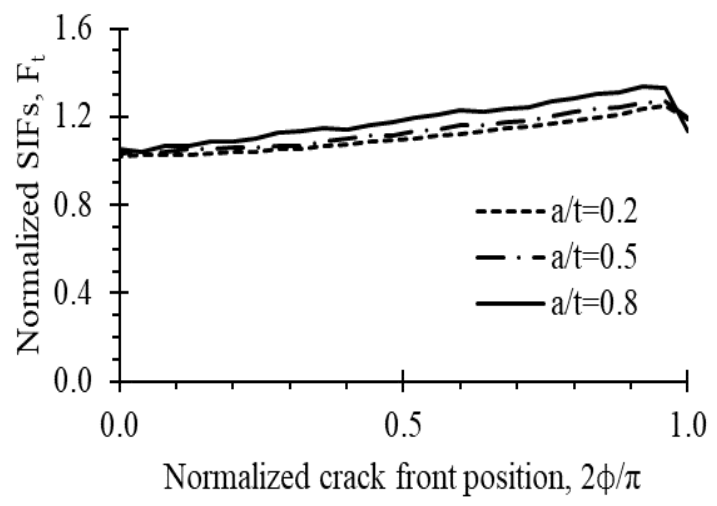

Fig. 6- The normalized stress intensity factors along the crack front for internal semi-elliptical crack located on a cylinder subjected to remote tension where (a) $\mathrm{a} / \mathrm{c}=0.4$ (b) $\mathrm{a} / \mathrm{c}=0.6$ (c) $\mathrm{a} / \mathrm{c}=0.8$ (d) $\mathrm{a} / \mathrm{c}=1$, and (e) $\mathrm{a} / \mathrm{c}=1.2$.

\subsection{Cracked cylinder under internal pressure}

A cracked cylinder with circumferential semi-elliptical crack was examined under internal pressure loading condition, the crack located either on the external or internal surface of the cylinder. The crack aspect ratio used to range between 0.4 to 1.2 , and relative crack depth $0.2,0.5$ and 0.8 . 
(a) $-\mathrm{a} / \mathrm{c}=0.4$

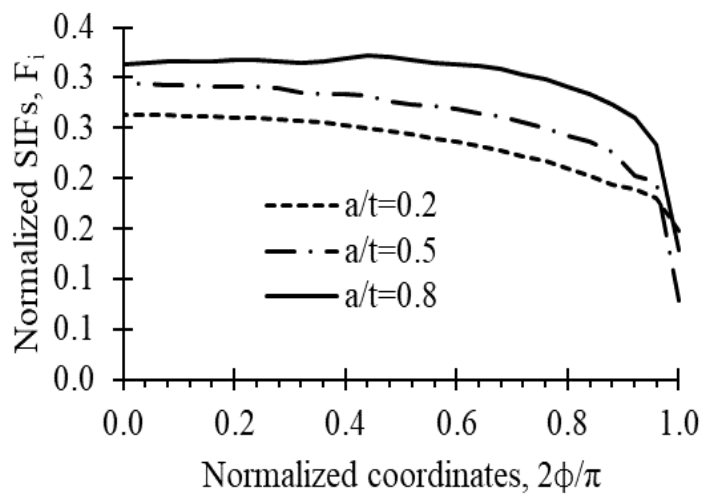

(c) $-\mathrm{a} / \mathrm{c}=0.8$

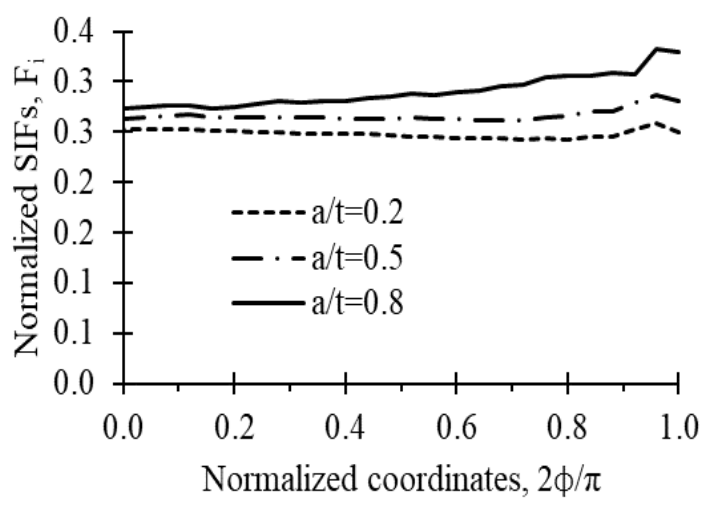

(b) $-\mathrm{a} / \mathrm{c}=0.6$

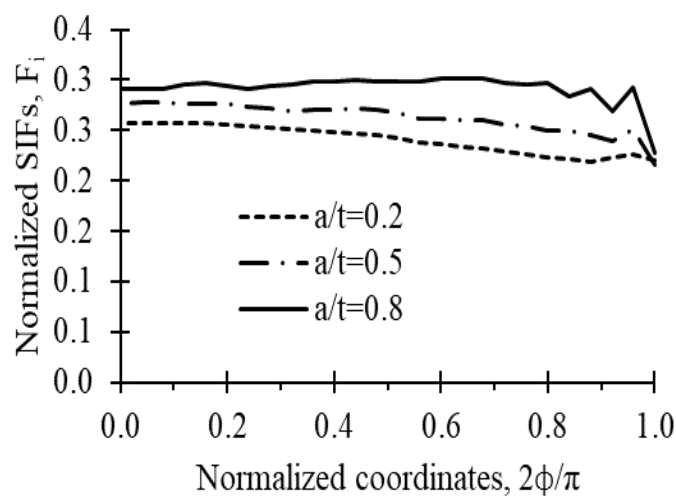

(d) $-\mathrm{a} / \mathrm{c}=1$

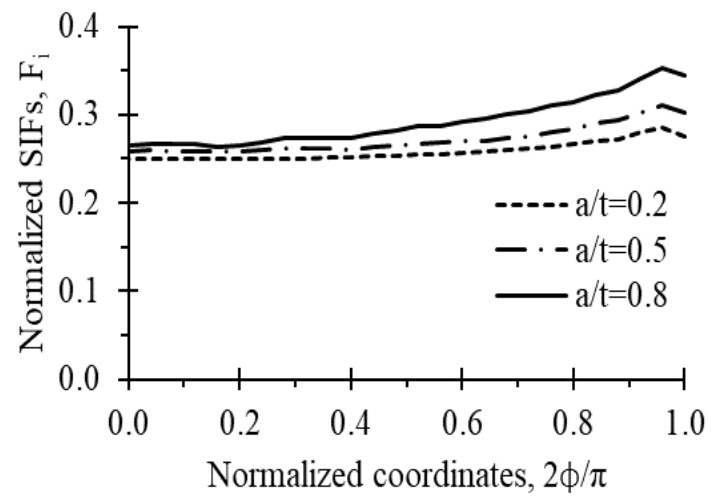

(e) $-\mathrm{a} / \mathrm{c}=1.2$

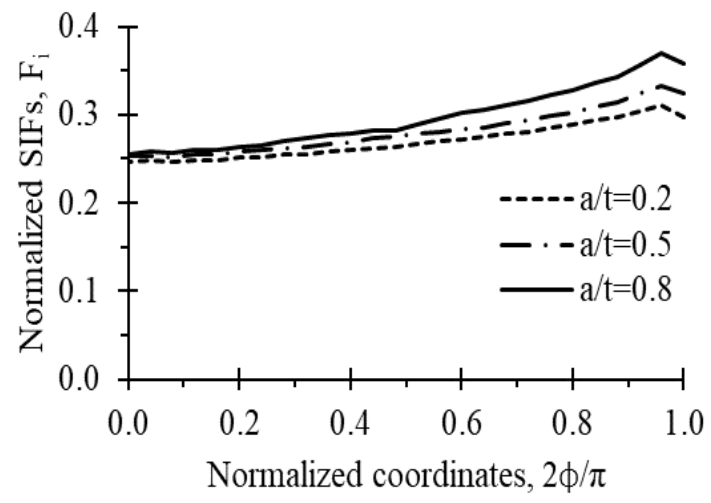

Fig. 7- The normalized stress intensity factors along the crack front for external semi-elliptical crack located on a cylinder subjected to internal pressure where (a) $\mathrm{a} / \mathrm{c}=0.4$ (b) $\mathrm{a} / \mathrm{c}=0.6$ (c) $\mathrm{a} / \mathrm{c}=0.8$ (d) $\mathrm{a} / \mathrm{c}=1$, and (e) $\mathrm{a} / \mathrm{c}=1.2$.

Figure 7 shows the distribution of the normalized SIFs under internal pressure, $F_{i}$, as a function of the normalized crack coordinates of the crack front for a circumferential crack located on the external surface of the cylinder. All $F_{i}$ values found to be symmetric along the crack front, and following different curve shapes depend on the applied aspect ratio value. For $a / c \leq 0.6, F_{i}$ following a convex curve shape, where the maximum SIFs value located at the deepest point on of the crack front (point B) and gradually decreases towards the surface point (A). For $0.6<a / c<0.75, F_{i}$ values following approximately straight line, where the values of SIFs along the crack front from point A till point B approximately are equal, which is the introduction to the well-known, transition effect, where the position of the maximum value of SIFs changes from point B to A. Due to this change or effect, $F_{i}$ values for $a / c>0.8$ following a concave curve shape, hence, the maximum value reached at a point near to the surface and slowly decrease towards point $\mathrm{B}$, where minimum value of SIFs lying. It is important to note that, $a / t$ has a significant effect on the $F_{i}$ value, any 
increase in this ratio causes an increase in $F_{i}$ value, which means, deep cracks are generally dangerous and could accelerate the fracture process than cracks that have less depth.
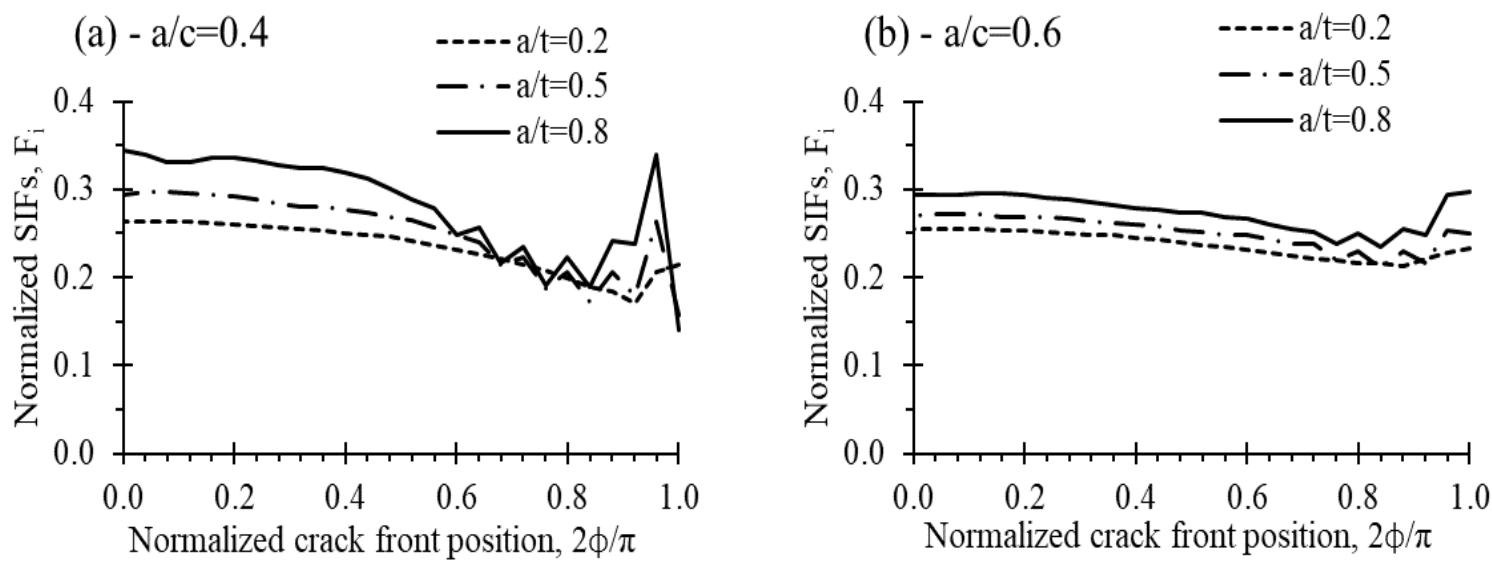

(c) $-\mathrm{a} / \mathrm{c}=0.8$

(d) $-\mathrm{a} / \mathrm{c}=1$
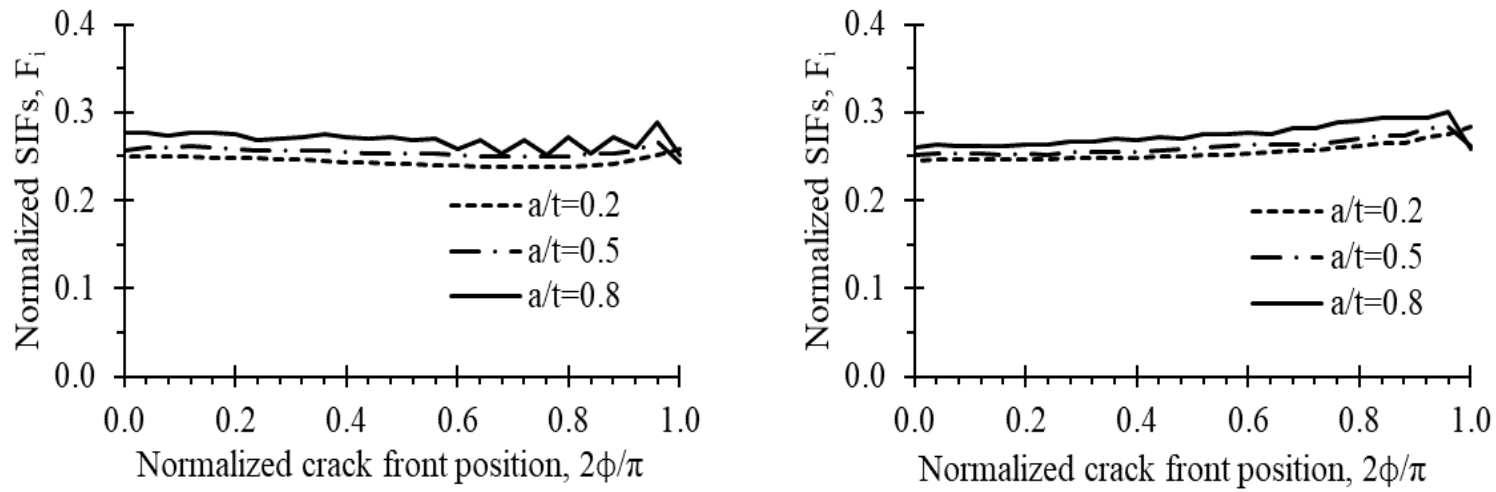

(e) $-\mathrm{a} / \mathrm{c}=1.2$

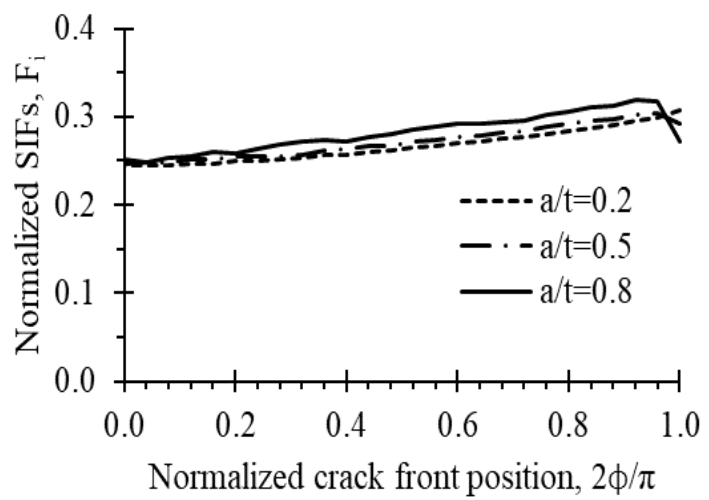

Fig. 8- The normalized stress intensity factors along the crack front for internal semi-elliptical crack located on a cylinder subjected to internal pressure where (a) $a / c=0.4$ (b) $a / c=0.6$ (c) $a / c=0.8$ (d) $a / c=1$, and (e) $a / c=1.2$.

Figure 8 shows the values of $F_{i}$ as a function of the normalized crack front coordinates for a semi-elliptical crack located on the inner surface of the cylinder. Again, the behaviour is similar to that shown by external crack, where, for small aspect ratios, the maximum SIFs located at point B on the crack front, while for high aspect ratios, the maximum SIFs located near point A. In addition, since the behaviour of $a / c$ for the internal crack was similar to that of external crack, $a / t$ has the same effect also, where any increase in $a / t$ ratio rase the value of $F_{i}$. Generally, SIFs values for external cracks found to be higher than those of internal crack for the same crack geometrical parameters and under the 
same internal pressure load, this is typical to all $a / c \geq 0.6$, but for $a / c$ less than 0.6 , SIFs values of the internal crack are slightly higher.

\section{Conclusion}

In this paper, ANSYS finite element analysis software was used to calculate the mode I stress intensity factors (SIFs) for semi-elliptical circumferential crack located either on the external or internal surface of a thick cylinder and subjected to two types of loading separately, tension and internal pressure. Based on the three-dimensional finite element analysis, the values of stress intensity factor were presented in non-dimensional form $F_{t}$ (normalized SIFs under tension loading), and $F_{i}$ (normalized SIFs under internal pressure loading). According to the numerical simulations, it is found that maximum values of SIFs located at the deepest points of the crack front for small crack aspect ratios, while it located at a point near to the surface for high crack aspect ratios. The relative depth of the crack has a significant effect on SIFs, where any increase in this ratio produces an increase in SIFs. In addition, the transition phenomenon can be noticed from the normalized SIFs distributions, that is, the maximum SIFs value attained at the deepest point for small crack aspect ratios, while it is located near to the outer point for high aspect ratios. Generally, the external crack in both loading examined cases showed slightly higher values of SIFs compare to those of internal crack except for small aspect ratios where SIFs for the internal crack approaches values higher than that of external crack.

\section{References}

[1] Lin XB, Smith RA. Fatigue growth prediction of internal surface cracks in pressure vessels. Journal of pressure vessel technology. 1998 Feb 1;120(1):17-23.

[2] Raju IS, Newman JC. Stress-intensity factors for internal and external surface cracks in cylindrical vessels. Journal of pressure vessel technology. 1982 Nov 1;104(4):293-8.

[3] Li CQ, Yang ST. Stress intensity factors for high aspect ratio semi-elliptical internal surface cracks in pipes. International Journal of Pressure Vessels and Piping. 2012 Aug 1; 96:13-23.

[4] Underwood JH. Stress intensity factors for internally pressurized thick-wall cylinders. In Stress Analysis and Growth of Cracks: Proceedings of the 1971 National Symposium on Fracture Mechanics: Part 11972 J ASTM.

[5] Diamantoudis AT, Labeas GN. Stress intensity factors of semi-elliptical surface cracks in pressure vessels by global-local finite element methodology. Engineering Fracture Mechanics. 2005 Jun 1;72(9):1299-312.

[6] Ismail AE, Jamian S, Kamarudin K, Mohd Nor MK, Ibrahim MN, Choiron MA. An Overview of Fracture Mechanics with ANSYS. Int J Integr Eng. 2018;10(5):59-67.

[7] Ismail AE, Ariffin AK, Abdullah S, Ghazali MJ. Stress intensity factors for surface cracks in round bar under single and combined loadings. Meccanica. 2012 Jun 1;47(5):1141-56.

[8] Ismail AE, Ariffin AK, Abdullah S, Ghazali MJ, Abdulrazzaq M, Daud R. Stress intensity factors under combined bending and torsion moments. Journal of Zhejiang University. Science A. 2012;13(1):1-8.

[9] Shin CS, Cai CQ. Experimental and finite element analyses on stress intensity factors of an elliptical surface crack in a circular shaft under tension and bending. International Journal of Fracture. 2004 Oct 1;129(3):239-64.

[10] Wang X, Lambert SB. Stress intensity factors and weight functions for longitudinal semi-elliptical surface cracks in thin pipes. International journal of pressure vessels and piping. 1996 Jan 1;65(1):75-87.

[11] Fett T. Estimation of stress intensity factors for semi-elliptical surface cracks. Engineering Fracture Mechanics. $2000 \mathrm{Jul} 1 ; 66(4): 349-56$.

[12] Shahani AR, Habibi SE. Stress intensity factors in a hollow cylinder containing a circumferential semi-elliptical crack subjected to combined loading. International journal of Fatigue. 2007 Jan 1;29(1):128-40.

[13] Predan J, Močilnik V, Gubeljak N. Stress intensity factors for circumferential semi-elliptical surface cracks in a hollow cylinder subjected to pure torsion. Engineering Fracture Mechanics. 2013 Jun 1; 105:152-68.

[14] Carpinteri A, Brighenti R, Spagnoli A. Fatigue growth simulation of part-through flaws in thick-walled pipes under rotary bending. International Journal of Fatigue. 2000 Jan 1;22(1):1-9.

[15] Carpinteri A, Brighenti R. Circumferential surface flaws in pipes under cyclic axial loading. Engineering Fracture Mechanics. 1998 Jul 1;60(4):383-96.

[16] Raju IS, Newman JC. Stress-intensity factors for circumferential surface cracks in pipes and rods under tension and bending loads. InFracture mechanics: seventeenth volume 1986 Jan. ASTM International.

[17] Zareei A, Nabavi SM. Calculation of stress intensity factors for circumferential semi-elliptical cracks with high aspect ratio in pipes. International Journal of Pressure Vessels and Piping. 2016 Oct 1; 146:32-8.

[18] ANSYS 19.0 Documentation (2019). ANSYS Company.

[19] Ismail, A.E., 2016. Mode I stress intensity factors of sickle-shaped surface cracks in round solid bars under bending moment. International Journal of Automotive \& Mechanical Engineering, 13(2).

[20] Carpinteri A. Shape change of surface cracks in round bars under cyclic axial loading. International Journal of Fatigue. 1993 Jan 1;15(1):21-6. 